\title{
Numerical simulation of Northwest Sabalan geothermal reservoir, Iran
}

\author{
Younes Noorollahi ${ }^{1 *}$, Ryuichi Itoi $^{2}$ \\ ${ }^{1}$ Dep. of Environmental and Energy, Sciences and Research Branch, IAU, Pounak, Tehran, Iran \\ ${ }^{2}$ Dep. of Earth Resources Engineering, Kyushu University, Fukuoka, Japan \\ *Corresponding author. Tel: +98 21 44865320, Fax: +98 21 44865002, E-mail: hashtroudi@srbiau.ac.ir
}

\begin{abstract}
A three dimensional numerical model of the northwest Sabalan geothermal system was developed on the basis of a conceptual model drawn from the analysis of the available field data. A numerical model of the reservoir was expressed with a grid system of a rectangular prism of $12 \mathrm{~km} \times 8 \mathrm{~km}$ with $4.6 \mathrm{~km}$ height, giving a total area of $96 \mathrm{~km}^{2}$. The model has 14 horizontal layers ranging in thickness between $100 \mathrm{~m}$ to $1000 \mathrm{~m}$ extending from a maximum of 3600 to $-1000 \mathrm{~m}$ a.s.l. Fifteen rock types were used in the model to assign different horizontal permeabilities from $5.0 \times 10^{-18}$ to $4.0 \times 10^{-13} \mathrm{~m}^{2}$ based on the conceptual model. Natural state modeling of the reservoir was performed, and the results indicated good agreements with measured temperature and pressure in wells. Numerical simulations were conducted for predicting reservoir performances by allocating production and reinjection wells at specified locations. Two different exploitation scenarios were examined for sustainability of reservoir for the next thirty years. Effects of reinjection location and required number of makeup wells to maintain the specified fluid production were evaluated. The results showed that reinjecting at Site B is most effective for pressure maintenance of the system.
\end{abstract}

Keywords: Geothermal, Reservoir, Simulation, Capacity, Sabalan, Iran

\section{Introduction}

In this study, simulation for natural state and capacity assessment of the reservoir were undertaken for the primary purpose of predicting and assessing the response of the NW Sabalan geothermal reservoir to the planned development scenarios. The computer codes of TOUGH2 [1] and AUTOUGH2 [2] were used with the equation of state of water and steam (EOS1). Different production scenarios were examined by numerical simulations for evaluating the reservoir responses, and consequently the optimum future development scenario was defined. Three exploration wells, NWS1, NWS3 and NWS4, were drilled in the study area based on the results of geological, geochemical and geophysical studies. According to the geophysical surveys, deep geothermal reservoir may extend from northeast to southwest where exploration wells were drilled along this suitability area $[3,4,5]$.

\section{Conceptual model of NW Sabalan reservoir}

Before a numerical simulation model of a given geothermal field being set up, a conceptual model must be developed. The model is usually represented by sketches showing a plan view and vertical sections of the geothermal system. On these sketches the most important features such as geothermal surface manifestations, hydrological boundaries, main geologic features such as faults and geological layers, zones of high and low permeabilities, location of deep inflows and boiling zones need to be involved. Thus, developing a conceptual model requires the synthesis of information from a multi-disciplinary team. The geological map of the Sabalan area with main surface manifestation, geological structures shown in Figure 1. A conceptual model of the study area was drawn along AB line in Figure 1, with $12 \mathrm{~km}$ length, from north to south. Three drilled exploration wells were projected on the AB line [6] and Subsurface geology of the area is described along cross section $\mathrm{AB}$, using geological data and information from three deep and two shallow exploration wells. In the central part of the model, Dizu formation presents and extends to the depth of about 200m a.s.l. This formation clearly exposed in the area where Wells NWS1 and NWS3 are located throughout the Valhezir formation reaches to the surface in the east of Well NWS4 and extends to $700 \mathrm{~m}$ 
depth in the whole study area from top or below Dizu formation. In the northern part of the area where Well NWS3 was drilled, geological unit is comprised of andesitic lava flows, tuff and tuff breccia that belong to Dizu formation of Neogene to Quaternary and Mejendeh metamorphics of Paleozoic in descending order down to $1000 \mathrm{~m}$ below sea level. Magnetotelluric (MT) survey was carried out in 1998 with 212 stations [6]. Nineteen measurement stations were located along the $\mathrm{AB}$ line, and the results were analyzed which shows two anomalies of low resistivity in south and north part and a high resistivity in the central part which can represent the location of an intrusive body beneath Well NWS4. Temperature contours are drawn using measured temperatures in exploration wells. The temperature increases from north to south which suggests that an upflow zone of high temperature fluid likely presents in the southern part of the field. Thus, Faults NW3, NNW5, NE5, NNW2 and NW4 play as upflow zone of the system. By integrating the subsurface geology from the wells with resistivity and temperature data, the conceptual model of the system can be illustrated in Figure 2. Differences of subsurface geology revealed from drilling between Wells NWS4 and NWS3 support the presence of Fault NE2. Temperature profiles of these two wells also show differences, which implies that Fault NE2 plays as an impermeable or low permeable boundary. The presence of slightly high resistivity zone beneath Site B can be interpreted as the existence of a diorite porphyry intrusive body. It has been assumed that geothermal fluids ascend through Faults NW3, NNW5, NE5, NNW2 and NW4. This faulted area can be an upflow zone of the system. The fluids would ascend through this fault zone to higher elevations and then flow horizontally in shallow layers to the northward due mainly to gravitational force and discharge through hot springs in lower elevations.

\section{Development of numerical model}

\subsection{Grid system and rock type and properties}

The NW Sabalan geothermal system was modeled with a rectangular prism $12 \mathrm{~km}$ long, 8km wide and $4.6 \mathrm{~km}$ depth. The model has 14 horizontal layers, AA to PP, ranging in thickness between 100 to $1000 \mathrm{~m}$ extending from a maximum of 3600 to $-1000 \mathrm{~m}$ a.s.l with 2595 grid blocks in total. For neglecting water-air unsaturated zone, first two top layers, AA and BB, were discarded from the model. Each layer has 192 grid blocks $500 \times 500$ and $1000 \times 1000 \mathrm{~m}$. The exploration drilling area is located in the center of the model, covering an area of $3 \times 5 \mathrm{~km}$. Permeability values were given to the model in ranges from $5.0 \times 10^{-17}$ to $4.0 \times 10^{-13} \mathrm{~m}^{2}$, with the maximum value in the shallow permeable horizon on depth between 1900 and $1400 \mathrm{~m}$ a.s.l (Figure 3). Sixteen rock types were used mainly for assigning different permeability. Porosity, rock density and thermal conductivity were $0.1,2500 \mathrm{~kg} / \mathrm{m}^{3}$ and $2.5 \mathrm{~W} / \mathrm{m}^{2 \circ} \mathrm{C}$ to all rocks. Rock parameters corresponding to the optimum natural state model are summarized in Table 2. The rock types CAP01, TOP01 and TOP02 with lowest permeability were assigned to layers CC, DD and EE which represent the cap rock of the system. The MAKH0 with low permeability was assigned to the northern part of the field below Site C to layers FF, GG, HH, and II. The rock LOW01 was given to the deep part in C area from 1400-500m a.s.l. corresponding to the metamorphosed rocks appeared in Well NWS3. The TOP04 was assigned to the area beneath Site $\mathrm{B}$ and surroundings for representing the conductive temperature profile observed in Well NWS4. This rock types appears in elevation from 2000$1400 \mathrm{~m}$ a.s.l. belong to the layers EE, FF, GG, HH and II. The MAKH1 rock type with high permeability was for the layer MM in Site B. The MAKH2 was assigned to the layers EE, FF, GG, HH and II from elevation of 2000-1400m a.s.l. according to information from Wells NWS1 and NWS4 as high permeable rock formations were found in these horizons. The LOW02 was used to the grid blocks in the layers KK and LL in the southern and central part and represent low permeability between two high permeable layers. The UPFLO rock type indicates the upflow zone with high vertical permeability. Six grid blocks $(500 \times 500 \mathrm{~m})$ in 
southern part were assigned with this rock type from layer PP to GG. Information from two wells, NWS1 and NWS4 indicates that there are two main permeable horizons in the reservoir: a shallow zone between 1800 and $1400 \mathrm{~m}$ a.s.l. in southern part, and a deeper zone between $500 \mathrm{~m}$ a.s.l. and sea level in both wells. In the computational grid system, the uppermost high permeable horizon in the reservoir was therefore subdivided into four layers (FF, GG, HH and II). The layer MM denotes the deep permeable horizon. The layers AA and $\mathrm{BB}$ represent the unsaturated zone, which were discarded from computing. This geothermal field is located in an arid area and two top layers are unsaturated. We can model such condition by using EOS3 with all layers or EOS1 be neglecting unsaturated zone.

Table 1 Rock parameters of the best natural-state model

\begin{tabular}{llllllll}
\hline \multirow{2}{*}{$\begin{array}{l}\text { Rock } \\
\text { type }\end{array}$} & $\begin{array}{l}\text { Density } \\
\left(\mathrm{kg} / \mathrm{m}^{3}\right)\end{array}$ & $\begin{array}{l}\text { Porosity } \\
(\%)\end{array}$ & $\mathrm{Kx}$ & $\mathrm{Ky}$ & $\mathrm{kz}$ & $\begin{array}{l}\text { Permeability }\left(\mathrm{m}^{2}\right) \\
\left(\mathrm{W} / \mathrm{m}^{2 \circ} \mathrm{C}\right)\end{array}$ & $\begin{array}{l}\text { heat } \\
\left(\mathrm{J} / \mathrm{kg}{ }^{\circ} \mathrm{C}\right)\end{array}$ \\
\hline ATMOS & 2500 & 99 & $2.5 \times 10^{-14}$ & $2.5 \times 10^{-14}$ & $2.5 \times 10^{-14}$ & 2.50 & $9.0 \times 10^{5}$ \\
CAP01 & 2500 & 10 & $2.0 \times 10^{-16}$ & $2.0 \times 10^{-16}$ & $7.0 \times 10^{-17}$ & 2.50 & $1.0 \times 10^{3}$ \\
BASE1 & 2500 & 10 & $6.0 \times 10^{-15}$ & $6.0 \times 10^{-15}$ & $3.0 \times 10^{-15}$ & 2.50 & $1.0 \times 10^{3}$ \\
BOND1 & 2500 & 10 & $9.5 \times 10^{-16}$ & $9.5 \times 10^{-16}$ & $6.6 \times 10^{-16}$ & 2.50 & $1.0 \times 10^{3}$ \\
TOP01 & 2500 & 10 & $5.5 \times 10^{-16}$ & $5.5 \times 10^{-16}$ & $1.1 \times 10^{-16}$ & 2.50 & $1.0 \times 10^{3}$ \\
TOP04 & 2500 & 10 & $5.0 \times 10^{-15}$ & $5.0 \times 10^{-15}$ & $1.1 \times 10^{-15}$ & 2.50 & $1.0 \times 10^{3}$ \\
BASE3 & 2500 & 10 & $1.0 \times 10^{-17}$ & $1.0 \times 10^{-17}$ & $5.0 \times 10^{-18}$ & 2.50 & $1.0 \times 10^{3}$ \\
LOW01 & 2500 & 10 & $6.0 \times 10^{-14}$ & $6.0 \times 10^{-14}$ & $1.0 \times 10^{-14}$ & 2.50 & $1.0 \times 10^{3}$ \\
MAKH3 & 2500 & 10 & $2.0 \times 10^{-13}$ & $2.0 \times 10^{-13}$ & $5.0 \times 10^{-14}$ & 2.50 & $1.0 \times 10^{3}$ \\
MATRX & 2500 & 10 & $5.0 \times 10^{-15}$ & $5.0 \times 10^{-15}$ & $1.0 \times 10^{-15}$ & 2.50 & $1.0 \times 10^{3}$ \\
TOP02 & 2500 & 10 & $5.0 \times 10^{-16}$ & $5.0 \times 10^{-16}$ & $2.0 \times 10^{-16}$ & 2.50 & $1.0 \times 10^{3}$ \\
MAKH0 & 2500 & 10 & $5.0 \times 10^{-15}$ & $2.0 \times 10^{-15}$ & $5.5 \times 10^{-16}$ & 2.50 & $1.0 \times 10^{3}$ \\
LOW02 & 2500 & 10 & $7.0 \times 10^{-16}$ & $7.0 \times 10^{-16}$ & $1.5 \times 10^{-16}$ & 2.50 & $1.0 \times 10^{3}$ \\
MAKH1 & 2500 & 10 & $1.0 \times 10^{-15}$ & $1.0 \times 10^{-15}$ & $5.0 \times 10^{-16}$ & 2.50 & $1.0 \times 10^{3}$ \\
MAKH2 & 2500 & 10 & $4.0 \times 10^{-13}$ & $4.0 \times 10^{-13}$ & $7.0 \times 10^{-14}$ & 2.50 & $1.0 \times 10^{3}$ \\
UPFLO & 2500 & 10 & $3.0 \times 10^{-13}$ & $3.0 \times 10^{-13}$ & $3.0 \times 10^{-13}$ & 2.50 & $1.0 \times 10^{3}$ \\
\hline
\end{tabular}

\subsection{Initial and boundary conditions}

The peripheral boundaries are impermeable for mass and adiabatic for heat. Grid blocks were filled with $15^{\circ} \mathrm{C}$ of water and pressure was equilibrated as an initial condition. High temperature fluid recharges at a rate of $90 \mathrm{~kg} / \mathrm{s}$ of $1159 \mathrm{~kJ} / \mathrm{kg}$ from the bottom layer was given through regional faults in the southwest region. The temperature of inflow geothermal fluid was calculated using geochemical geothermometers [6] and also slightly changed by trial and error manner through iterative process of natural state simulation. According to a vertical temperature distribution across $\mathrm{AB}$ cross section using data from the wells an upflow zone may present about $2.5 \mathrm{~km}$ to the southeast of Well NWS1. The recharge was assigned to the grid blocks of 89, 92, 103, 105, 109 and 111 in PP layer. A flow rate of 8kg/s of low temperature, $130^{\circ} \mathrm{C}$, inflow was assigned to the grid 4 in northwestern part to simulate the temperature and pressure condition of the northern part close to Well NWS3. Natural discharge from the field was modeled using deliverability method. The productivity index (PI) was calculated on deliverability model [1] and well bottom pressures $\left(\mathrm{P}_{\mathrm{wb}}\right)$ were obtained by trial-and-errors manner. Mass flow rate on deliverability is proportional to the pressure difference between the grid block and a prescribed pressure that is lower than that of the block. There are several hotspring with surface temperatures from 25 to $85^{\circ} \mathrm{C}$ and the flow rate of about $50 \mathrm{~kg} / \mathrm{s}$. In order to reproduce the hot spring activity in the numerical model, 
fluid production based on deliverability was utilized in three blocks in layers FF (51, 78, and 183) and one block in layer II (130). Heat flux was given to the blocks in the bottom layer, $\mathrm{PP}$, of the model as a conductive heat supply. A heat flux of $200 \mathrm{~mW} / \mathrm{m}^{2}$ was used as the initial basis for calculating the heat inflow in southern and central parts.

\subsection{Wells data matching and model validation}

The validation process normally involves comparing the computed results against measured temperature and pressure in three wells. This pressure are measured as stationary pressure measurement of single major feed zone during well testing. The matches between the measured and computed values were improved primarily by adjusting the permeability, fluid flow rate and specific enthalpy of the high-temperature recharge assigned to the bottom six grid blocks. Also the lower temperature in Well NWS3 was reproduced in the model by assigning an inflow from grid block 4 in the northwestern part.

\section{Production prediction simulations}

Once a reasonable numerical model of the natural state of reservoir has been developed, it can be used as an initial model for future prediction performances upon various exploitation scenarios. Main concern of prediction in terms of reservoir management is to examine whether the reservoir can produce required steam for specified period of the present state or is able to produce more steam within acceptable effects or changes in reservoir conditions. Two different exploitation scenarios are designed and then examined for future reservoir performances in this field. Wells on deliverability have been used for evaluating production rate of wells during prediction calculations. The well productivity depends on the well bottom pressure $\left(\mathrm{P}_{\mathrm{wb}}\right)$ where the reservoir pressure will decreases during production, and if the reservoir pressure draw down to equal to the $\mathrm{P}_{\mathrm{wb}}$, the well cannot produce the fluid. Numerical simulations were carried out using the AUTOUGH2 simulator for 30 years from year 2015. Numerical simulations were conducted for predicting reservoir performances by assigning production and reinjection wells. The production zones are located in the southern area on Sites A, D and E (Figure 1). These areas situated in a junction of Faults NNW2, NNW3, NNW5, NE5, NE6, NW3, NW4 and NW5 where high permeable fractured zones can be developed along these faults. The northern part of the field with lower elevation was recommended for reinjection. Reinjecting geothermal waste water to these localities with different arrangement was examined on production scenarios. The simulations were run for 30 years of production. The recharge flow rate of the high temperature fluid to the system may increases upon production due to reservoir pressure drop. In prediction simulations, however, constant recharge flow rate was assumed as same as the natural state $(98 \mathrm{~kg} / \mathrm{s})$. Prediction for NW Sabalan geothermal projects was simulated for two different cases for two power output scenarios; Scenario II: 50MW; Case 1: with drilling makeup wells and; Case 2: without drilling makeup well and; Scenario III: 100MWe; Case 1: with drilling makeup wells and Case 2: without drilling makeup well. In these scenarios, declines of pressure, temperature, enthalpy and mass rates of fluid and steam productions of wells were evaluated. The mass production rates of fluid and steam were calculated from fluid discharges of production blocks at a separator pressure of 5.5bar. The reinjection rate of wastewater and its enthalpy into reservoir were given as that of the separator pressure and temperature of $155^{\circ} \mathrm{C}$. On the basis of discharge data from Well NWS4, required amount of geothermal fluid for a proposed single flash power plant was calculated [7]. The input parameters are; produced fluid enthalpy $985 \mathrm{~kJ} / \mathrm{kg}$, separation pressure $5.5 \mathrm{bar}$, condenser pressure, $0.1 \mathrm{bars}$, outlet temperature $46^{\circ} \mathrm{C}$ and isentropic efficiency of the turbine 0.78. By assigning these inputs and output information, required production rate of geothermal fluid for different scenarios and number of wells are summarized in Table 2. 


\subsection{Scenario II: 50 MWe power production}

In this scenario for $50 \mathrm{MWe}$ generation, total amount of $690 \mathrm{~kg} / \mathrm{s}$ of the geothermal fluid is required. This amount of geothermal fluid was assigned to produce initially from 13 production wells which are fed from the layer MM. For reinjection of the wastewater, seven wells were allocated in the northern and central parts (Site B area) of the field. Two different cases in this scenario were simulated and the effects of production on total mass and steam productions, reservoir pressure, temperature, average flowing enthalpy and natural discharge rates were evaluated. To optimize the production scheme two production and injection cases were designed for this scenario including; Case 1 : 50 MWe steady power production with makeup wells and Case 2: 50 MWe power production without makeup well.

Table 2 Characteristics of the production scenarios

\begin{tabular}{lccc}
\hline \multicolumn{1}{c}{ Item } & Scenario II Case1 & Scenario II Case2 & Scenario III \\
\hline Power output (MWe) & 50 & 50 & 100 \\
Total production (kg/s) & 690 & 690 & 1380 \\
Steam production (kg/s) & 106 & 106 & 212 \\
Brine production (kg/s) & 584 & 584 & 1168 \\
Number of prod. well & 13 & 13 & 35 \\
Number of reinj. well & 7 & 7 & 16 \\
makeup wells & 7 & 0 & 5
\end{tabular}

In Case 1; the base level was designed to produce 50MWe over 30 years. Because of pressure drop during production, steam flow rate as well as total production rate decrease. When the steam production rate decreases to $90 \%$ of the designated level or power generation drop below 45MWe, new makeup wells start to production for maintaining the total production rate. In Case 2 no makeup well was assigned and the production from 13 wells was maintained over 30 years and the behavior of the reservoir was monitored. Table 5 summarizes the production and reinjection flow rates and grid blocks.

\subsubsection{Steam flow rates}

Steam flow rates versus time for two cases in Scenario II are presented in Figure 4. In early times, production rates rapidly decease with time in both cases. In Case 1, steam production rate decreases below $95 \mathrm{~kg} / \mathrm{s}$ after 3 years of production and then a makeup well starts to production. This new well can keep the power production more than $45 \mathrm{MWe}$ for two years and another new makeup well was required. In this scenario seven makeup wells in total were required in years at 2018, 2020, 2023, 2026, 2029, 2033, and 2038 to keep the power generation of 45MWe for 30 years. In Case 2 the makeup well was not assigned and production was continued by 13 initially drilled wells over 30 years. The steam production rate decreases rapidly in the first 5 years with an average of 3.5\% per year. From the year 2020 to 2030 the decline rate is moderated to $1.2 \%$ per year and in the next 15 years (20302045 ) the steam flow reduces only $0.31 \%$ per year. It can be concluded that the production rate eventually stabilize after 15 years of production. In this case, total production rate drops by $34 \%$ in 30 years.

\subsubsection{Predicted pressure and temperature}

Pressure and temperature changes of the reservoir were monitored while running this production scenario for 30 years. Changes of the pressure and temperature from their initial 
values at shallow and deep layers are evaluated. Temperature drops in layers $\mathrm{HH}$ and $\mathrm{MM}$ for Case 1. In Layer $\mathrm{HH}$ temperature drop is less than $1^{\circ} \mathrm{C}$. In the main producing layer of $\mathrm{MM}$, cooling occurs in the northern part of the reservoir in reinjection area. Decrease amount of temperature shows up to $60^{\circ} \mathrm{C}$ in the central part of the reinjection zone and the area of $10^{\circ} \mathrm{C}$ cooling extends over $4.5 \mathrm{~km}^{2}$. Low temperature front moves from reinjection area to the southward of production zone. Actually, the temperature drop in production zone is only about $1^{\circ} \mathrm{C}$. As shown in the figures cooling in main production and reinjection layer, $\mathrm{MM}$, is more apparent than layer HH. Pressure changes also occurred in layers HH and MM. Pressure drops at layer $\mathrm{HH}$ are in the range of 4-11 bard . Largest pressure drop occurs in the main production zone in the southern part. In Layer MM the pressure drop in production zone is larger than that in Layer $\mathrm{HH}$, and reaches up to 12 bar of pressure drop in the central part of the production zone. In reinjection area, pressure increases up to 50bar due to reinjection of large amount of the waste water.

\subsection{Scenario III: 100 MWe power production}

The largest power generation of 100MWe was examined for Scenario III. This requires a production of $1380 \mathrm{~kg} / \mathrm{s}$ of the geothermal fluid. For this scenario, total number of 35 production and 16 reinjection wells were assigned. The grid number corresponding to each production and reinjection wells and assumptions of the scenario is presented in Table 5. However, thirty five production wells is a large number, and it causes higher cost per $\mathrm{kW}$ of electricity generation. This scenario was given to evaluate the maximum production capacity of the field. As one well can be assigned in one grid, the maximum number of production wells being allocated is forty in the production zone. Thus, five wells can be allocated as the maximum number of makeup wells. One makeup well was allocated every 5 years for this scenario.

\subsubsection{Total flow rate and flowing enthalpy}

Figure 5 presents the total production rate with time. By starting the simulation with total flow rate of $1380 \mathrm{~kg} / \mathrm{s}$ the flow rate declines rapidly in both cases in 5 years. The result clearly indicates that adding five makeup wells do not increase the total production rate. The total production rate decreases to $600 \mathrm{~kg} / \mathrm{s}$ after 10 years. This corresponds to steam production for electricity generation of 47MWe. Based on the currently available subsurface information this field can produce $100 \mathrm{MWe}$ electricity for a short period, 5 years, and then decline to about $50 \mathrm{MWe}$ in following years. Total number of 35 production wells of $3000 \mathrm{~m}$ depth makes the total length of $100 \mathrm{~km}$ of drilling in this field. Consequently, electricity generation rate can be 1MWe per one kilometer of drilling in early stage of the production, but it is predicted to be decreased in the later years. World average rate is $2-5 \mathrm{MWe} / \mathrm{km}[8,9]$ which is much higher than this value. To evaluate the effects of total number of wells on average well output the simulations were carried out with different number of wells, from 5 to 35 wells. The results show that average production rate of each well decrease with an increase of the total number of the wells. Figure 6 illustrates relationship between average well output and the total number of the production well. For 5 to 15 wells the average well output is $1.3 \mathrm{MWe} / \mathrm{km}$, which is still lower than the world average but output reduces to $0.8 \mathrm{MWe} / \mathrm{km}$ by increasing the number of wells. This is considerably low and results in an increase of the electricity production cost. The simulation was run for 100 years to find out the reservoir capacity that can deliver steam at stabilized rate. Results show that after 20 years the steam flow rate reaches stable with rate of $98 \mathrm{~kg} / \mathrm{s}$ which can generate 45-50MWe of electricity over 100 years. The flowing enthalpy does not change significantly during simulation period in both cases and the average flowing enthalpy of the produced fluid shows $998 \mathrm{~kJ} / \mathrm{kg}$. 


\subsubsection{Predicted pressure and temperature}

The temperature and pressure changes for scenario III were examined for Layers MM. Cooling occurs in the northern part of the reservoir where reinjection wells locate. Temperature drops by $80^{\circ} \mathrm{C}$ from the initial in the central part of the reinjection zone, and more than $10^{\circ} \mathrm{C}$ cooling can be seen over an area about $7 \mathrm{~km}^{2}$ which is $4.5 \mathrm{~km}^{2}$ in Scenario II. In Layer MM the pressure drop in the production zone is large and shows up to 30bar in the central part of the production zone. This pressure drops can cause the production rate decline. Larger pressure drop in Layer MM occurs in a wider area compared with that of Scenario II. In the reinjection area, pressure increases due to the reinjection of large amount of waste water. In reinjection area pressure increases up to 80bar.

\section{Conclusions}

A three dimensional numerical model of the NW Sabalan geothermal field was developed and calibrated by numerical simulations. Prediction simulations of reservoir behaviors were also carried out using the numerical model developed. Two hypothetical development scenarios were evaluated for production capacity assessment and reinjection effects on fluid production. The conclusions are summarized as

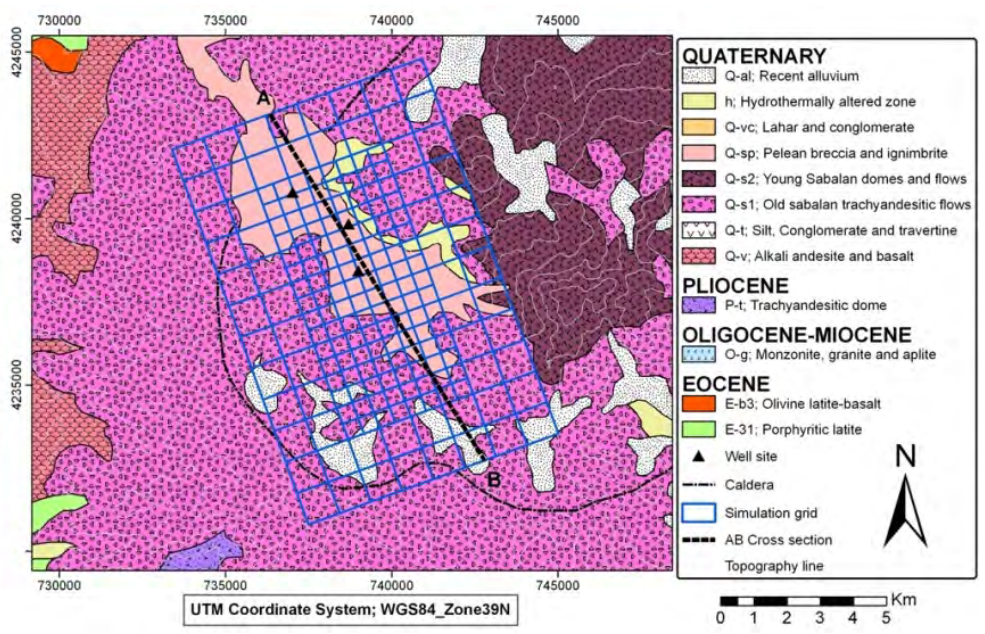

Figure 1 Geological map of the Sabalan area with grid system follows:

The results of natural state simulation using the AUTOUGH2 simulator indicated good agreements in temperature and pressure profiles of three deep wells with measurement. Reinjection of the waste water is effective for moderating reservoir pressure drop. The immediate adjacent area, north to the production area, named as Site B is recommend for locating reinjection wells because of more effective on the pressure support compared with reinjection at further north area, Site $\mathrm{C}$. Based on existing data and assumptions reservoir can sustain steam production equivalent to 50 MWe of electricity for 30 years or more. The reservoir can produce in maximum capacity for production of 90-100MWe for short period of time (5 years), but the production rate decreases gradually to the level of 50MWe after 20 years. The reservoir can sustain steam production for 50MWe over 100 years.

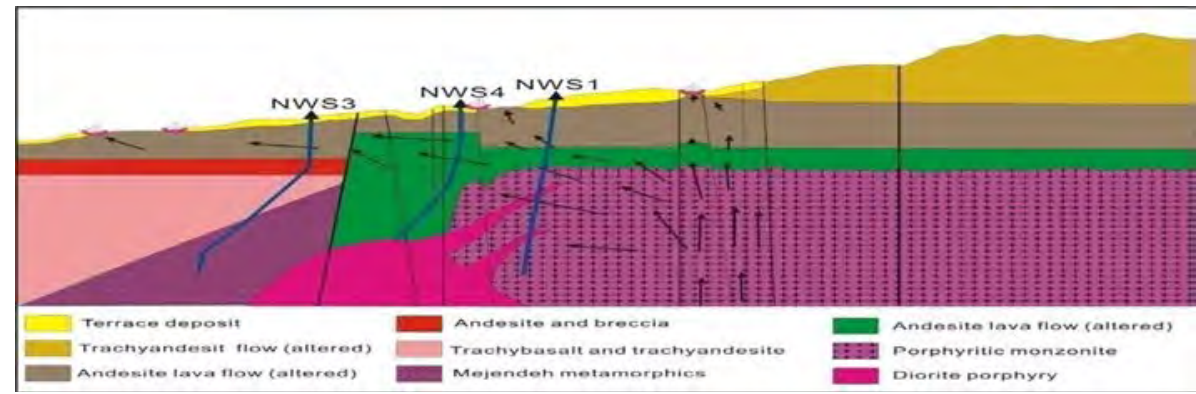

Figure 2 Conceptual model of the NW-Sabalan geothermal field 


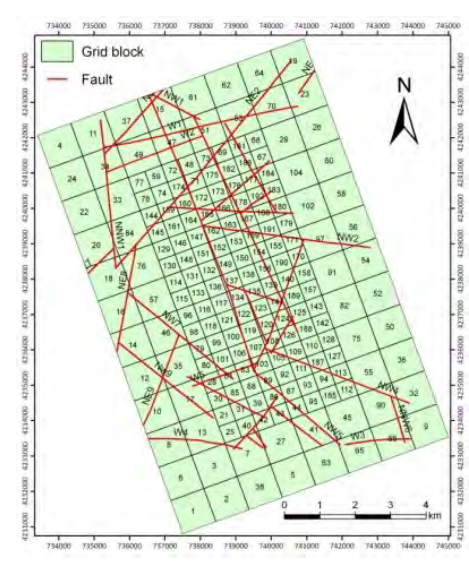

Figure 3 The grid system and faults in study area

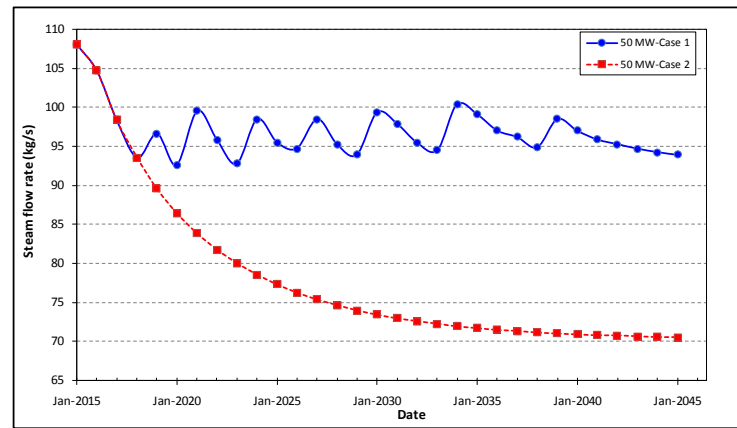

Figure 4 Steam flow rate change with time for Scenario II

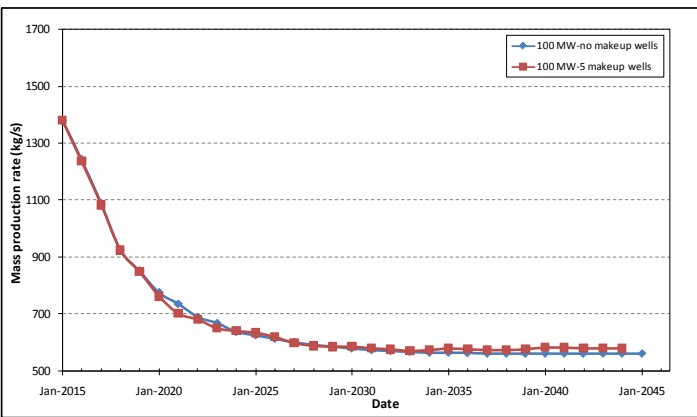

Figure 5 Total production rate over 30 years for Scenario III

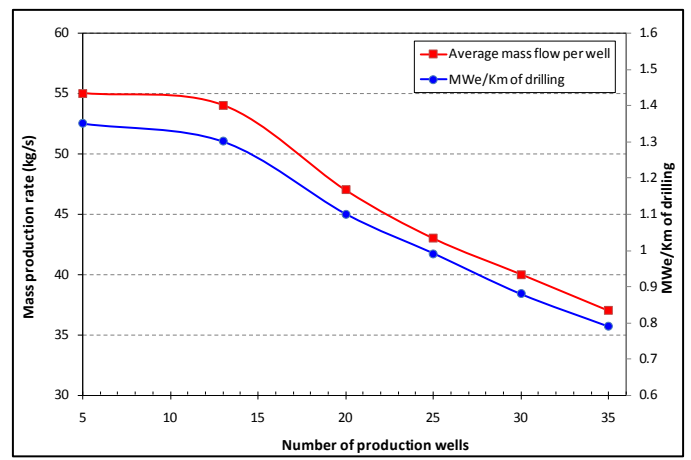

Figure 6 Relationship between average welloutput and power generation per $\mathrm{km}$ of drilling and number of the production well

\section{References}

[1] Pruess, K.,TOUGH2-A General Purpose Numerical Simulator for Multiphase Fluid and Heat Flow, Earth Science Division, Lawrence Berkeley Laboratory, Berkeley,1991,102p

[2] O’Sullivan, MJ., AUTOUGH2 Notes, Department of Engineering Science, University of Auckland, 2000,18 pp

[3] SKM, Report on completion tests and heat up surveys of well NWS1, SUNA Co., 2004a

[4] SKM, Well NWS3 drilling completion report, SUNA Co., 2004b,47 pp

[5] SKM, Well NWS4 drilling completion report, SUNA Co., 2004c, 43 pp

[6] SKM, Sabalan geothermal project, Stage1- surface exploration, final exploration report, report number. 2505-RPT-GE-003, SUNA Co., 1998,83 pp

[7] Beckman, W. and Klein, S., Engineering Equation Solver Professional Versions user manual, F-Chart Software, 2007, pp. 312

[8] Stefansson. V., Investment cost for geothermal power plants, Geothermics, Vol. 31, 2002, 263-272

[9] Stefansson. V., Success in geothermal development, Geothermics, Vol. 21, 1992, 823834 